Check for updates

Cite this: RSC Adv., 2018, 8, 42100

Received 13th August 2018

Accepted 13th December 2018

DOI: $10.1039 / \mathrm{c} 8 \mathrm{ra06793g}$

rsc.li/rsc-advances

\section{Color tuning and white light emission by codoping in isostructural homochiral lanthanide metal- organic frameworks $\uparrow$}

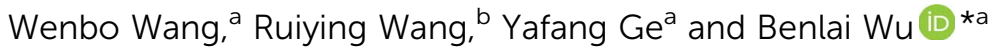

Four lanthanide-based homochiral metal-organic frameworks (Ln-HMOFs), $\left\{\left[\mathrm{Ln}_{2}(\mathrm{HL})_{2}\left(\mathrm{H}_{2} \mathrm{O}\right)_{4}\right] \cdot 2 \mathrm{Cl} \cdot 5 \mathrm{H}_{2} \mathrm{O}\right\}_{n}$ [Ln = Gd (1), Eu (2), Tb (3) and Dy (4)], have been synthesized through solvothermal reactions of chiral ligand (S)-5-(((1-carboxyethyl)amino)methyl)isophthalic acid $\left(\mathrm{H}_{3} \mathrm{~L}\right)$ with corresponding $\mathrm{LnCl}_{3} \cdot 6 \mathrm{H}_{2} \mathrm{O}$. They are binodal $(3,6)$-connected frameworks with kgd nets based on binuclear cluster units and zwitterionic $(\mathrm{HL})^{2-}$ linkers. Considering the isostructuralism of these Ln-HMOFs as well as the blue emission of compound 1 and the strong typical $\mathrm{Eu}^{3+}$ and $\mathrm{Tb}^{3+}$ emissions of compounds 2 and 3, single-phase mixedlanthanide HMOFs have been prepared by doping of $\mathrm{Ln}^{3+}$ into the $\mathrm{Ln}-\mathrm{HMOFs}$ to modulate light-emitting color. Interestingly, the bimetallic doped Eu/Tb-HMOFs $\left[\left(\mathrm{Eu}_{x} \mathrm{~Tb}_{1-x}\right)_{2}(\mathrm{HL})_{2}\left(\mathrm{H}_{2} \mathrm{O}\right)_{4}\right] \cdot 2 \mathrm{Cl} \cdot 5 \mathrm{H}_{2} \mathrm{O}$ display a fluent change of light-emitting color among green, yellow, orange, orange-red, and red by adjusting the doping concentration of $\mathrm{Eu}^{3+}$ ions into the Tb-HMOF. Very importantly, the trimetallic doped $\mathrm{Eu} / \mathrm{Gd} / \mathrm{Tb}-\mathrm{HMOF}$ $\left[\left(\mathrm{Eu}_{0.1388} \mathrm{Gd}_{0.6108} \mathrm{~Tb}_{0.2504}\right)_{2}(\mathrm{HL})_{2}\left(\mathrm{H}_{2} \mathrm{O}\right)_{4}\right] \cdot 2 \mathrm{Cl} \cdot 5 \mathrm{H}_{2} \mathrm{O}$ emits white light upon excitation at $355 \mathrm{~nm}$, whose emission can also be switched between different colors when excited with different ultraviolet light. Furthermore, the fluorescence response of $\mathrm{Tb}-\mathrm{HMOF}$ to various usual metal ions, and especially fluorescent sensing behaviours to $\mathrm{Fe}^{3+}, \mathrm{Cr}^{3+}$ and $\mathrm{Al}^{3+}$ have been preliminarily investigated.
\end{abstract}

\section{Introduction}

Further motivated by a longing for greener, safer and energy efficient light-emitting materials, the exploration of solid-state luminescent materials through various approaches including metal-doped or hybrid inorganic materials, ${ }^{\mathbf{1 - 3}}$ organic molecules, ${ }^{\mathbf{4}}$ polymers, ${ }^{5}$ nanomaterials, ${ }^{6}$ and metal complexes ${ }^{1}$ has evolved rapidly in recent years. Lanthanide metal-organic frameworks (Ln-MOFs) owing to their tunable structure diversities, ${ }^{7,8}$ attractive photophysical properties, and potential applications in biomedical imaging, ${ }^{9}$ lighting, ${ }^{10}$ and display devices ${ }^{7}$ make them promising candidates for the development of high-efficiency light-emitting materials. As is well known, lanthanide ions feature excellent luminescence properties such as long lifetime, large Stokes shift and narrow-band but the weak light absorption caused by Laporte forbidden $\mathrm{f}-\mathrm{f}$ transitions makes the direct lanthanide excitation inefficient. ${ }^{11}$ However, Ln-MOFs incorporating $\mathrm{Ln}^{3+}$ with judiciously selected organic linkers which can

${ }^{a}$ College of Chemistry and Molecular Engineering, Zhengzhou University, Zhengzhou 450001, P. R. China. E-mail: wbl@zzu.edu.cn; Tel: +86037167783126

${ }^{b}$ School of Chemical Engineering, Henan Vocational College of Applied Technology, Zhengzhou 450042, P. R. China

$\dagger$ Electronic supplementary information (ESI) available: Additional figures and tables, TGA, PXRD, IR spectra, excitation and emission spectra, decay curves (PDF)s. CCDC 1852703-1852706 for 1-4. For ESI and crystallographic data in CIF or other electronic format see DOI: $10.1039 / \mathrm{c} 8 \mathrm{ra06793} \mathrm{g}$ participate in efficient light absorption and ligand-to-metal energy-transfer processes through the so-called "antenna effect" can possibly overcome this paucity. ${ }^{\mathbf{1 2 - 1 4}}$ Additionally, the selfassemblies of varied $\mathrm{Ln}^{3+}$ ions with the same organic bridges under the same reaction conditions always result in isostructural Ln-MOFs due to very similar coordination environments of $\mathrm{Ln}^{3+}$ ions, which provides a facile platform for color tuning and white light emission through the doping of different $\mathrm{Ln}^{3+}$ ions into isostructural MOFs without disruption of the original structure. ${ }^{15-19}$ Currently, aromatic polycarboxylate ligands have been well explored in the formation of Ln-MOFs luminescence materials, not only because their carboxyl moieties can adopt multiple coordination modes to give high-dimensional unique structures with good thermal stability, but also because they can increase light absorption, provide blue color sources, and act as excellent sensitizers to activate $\mathrm{Ln}^{3+}$ ions. ${ }^{20-24}$

Homochiral metal-organic frameworks (HMOFs) have attracted special attention owing to their fascinating structures and intriguing potential applications in asymmetric catalysis and enantioselective separation. ${ }^{25-33}$ In contrast, studies on lanthanide-based homochiral metal-organic frameworks (LnHMOFs) as multicolor luminescence materials are still quite limited at present, although they have unique optical properties, such as nonlinear optics, circular dichroism and chiral polarized photoemission, ${ }^{\mathbf{1 6 3 4 - 3 7}}$ which could further expand its application in luminescent materials. Herein, $(S)$-5-(((1-carboxyethyl)amino)methyl)isophthalic acid $\left(\mathrm{H}_{3} \mathrm{~L}\right.$, Scheme 1$)$, a typical 
aromatic polycarboxylate linker being synthesized and used in our recent fabrication of novel transition metal HMOFs where $\mathrm{H}_{3} \mathrm{~L}$ ligand displays various existing forms and versatile coordination models and also transmits its chirality into the whole frameworks, ${ }^{38}$ was selected as a chiral bridge and sensitizer to construct Ln-HMOFs. We report the preparation of isostructural Ln-HMOFs, $\left\{\left[\operatorname{Ln}_{2}(\mathrm{HL})_{2}\left(\mathrm{H}_{2} \mathrm{O}\right)_{4}\right] \cdot 2 \mathrm{Cl} \cdot 5 \mathrm{H}_{2} \mathrm{O}\right\}_{n}[\mathrm{Ln}=\mathrm{Gd}(\mathbf{1}), \mathrm{Eu}(2)$, four $\mathrm{Tb}$ (3) and $\mathrm{Dy}(4)]$, and a series of single-phase mixedlanthanide HMOFs analogues. More importantly, color tuning and white light-emission can be easily attained by carefully adjusting the relative concentration of lanthanum ions in the resulting 2D Ln-HMOFs. Furthermore, crystal structure, circular dichroism, luminescent mechanism, color tuning, and cation sensing have been investigated in detail.

\section{Experiment}

\section{Materials and general procedures}

All the reagents were of analytical grade and obtained from commercial sources without further purification. Enantiopure ligand (S)-5-(((1-carboxyethyl)amino)methyl)isophthalic acid $\left(\mathrm{H}_{3} \mathrm{~L}\right)$ were prepared according to our reported procedure. ${ }^{38}$ Elemental analyses were performed with a Carlo-Erba 1106 elemental analyzer. IR spectra (KBr pellets) were recorded in the range $400-4000 \mathrm{~cm}^{-1}$ on a Nicolet NEXUS 470 FT-IR spectrophotometer (Fig. S1 $\dagger$ ). Thermal analysis curves were scanned from 30 to $800{ }^{\circ} \mathrm{C}$ under air on a STA 409 PC thermal analyzer (Fig. S2 $\dagger$ ). X-ray diffraction (PXRD) patterns of the samples were recorded on a RIGAKU-DMAX2500 X-ray diffractometer with $\mathrm{Cu}$ $\mathrm{K} \alpha$ radiation (Fig. $\mathrm{S} 3-\mathrm{S} 4 \dagger$ ). The luminescence spectra for the solid and suspension samples were determined at room temperature on a Hitachi F-4500 fluorophotometer with a xenon arc lamp as light source. The fluorescence lifetime $\tau$ was determined by a FLS980 fluorescence spectrometer. The emission quantum yield measurements were carried out on solid samples using an integrating sphere on an Edinburgh FLS980 fluorescence spectrometer. Solid-state circular dichroism (CD) spectra (KBr pellets) were recorded at room temperature on a MOS-450 spectrometer. Inductively coupled plasma (ICP) spectroscopy was detected on a Thermo ICAP 6000 DUO spectrometer. On the basis of international CIE standards, the Commission International de I'Eclairage (CIE) color coordinates were calculated. The general colour rendering index (CRI) were designated by the symbol $R_{\mathrm{a}}$, which is the average value of $R_{1}$ to $R_{8}{ }^{39,40}$ The numbers in parentheses indicate the Munsell colour system. ${ }^{41}$ The correlated colour temperature (CCT) values were obtained based on the corresponding CIE colour coordinates.

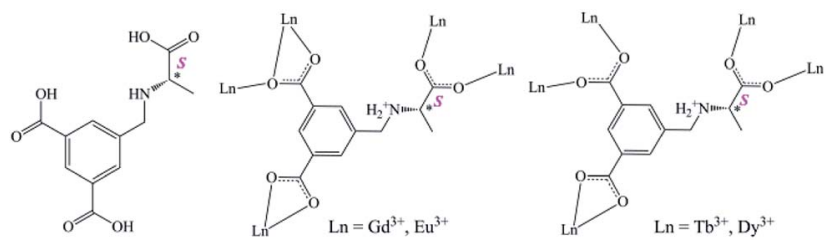

Scheme 1 Schematic representation of chiral ligand $H_{3} L$ and the coordination modes of its zwitterionic $(\mathrm{HL})^{2-}$ in 1-4.

\section{Synthesis of compounds}

All compounds including the mixed-lanthanide ones were synthesized in a similar procedure except for the different starting lanthanide salts. The synthesis of $\left\{\left[\mathrm{Gd}_{2}(\mathrm{HL})_{2}\left(\mathrm{H}_{2} \mathrm{O}\right)_{4}\right]\right.$. $\left.2 \mathrm{Cl} \cdot 5 \mathrm{H}_{2} \mathrm{O}\right\}_{n}(\mathbf{1})$ is detailedly introduced as a representative: a mixture of $\mathrm{H}_{3} \mathrm{~L}(0.0134 \mathrm{~g}, 0.05 \mathrm{mmol}), \mathrm{GdCl}_{3} \cdot 6 \mathrm{H}_{2} \mathrm{O}(0.0183 \mathrm{~g}$, $0.05 \mathrm{mmol})$, deionized $\mathrm{H}_{2} \mathrm{O}(0.5 \mathrm{~mL})$ and acetonitrile $(2 \mathrm{~mL})$ was sealed in a $25 \mathrm{~mL}$ Teflon-lined stainless autoclave and heated at $120{ }^{\circ} \mathrm{C}$ for $24 \mathrm{~h}$. After the mixture was cooled to room temperature at a rate of $5{ }^{\circ} \mathrm{C} \mathrm{h}^{-1}$, colorless block crystals were obtained, washed with distilled water, and dried in air, resulting in $62 \%$ yield (based on Gd). Anal. calcd for $\mathrm{C}_{24} \mathrm{H}_{40} \mathrm{Cl}_{2} \mathrm{Gd}_{2} \mathrm{~N}_{2} \mathrm{O}_{21}$ (\%): $\mathrm{C}$, 26.74; H, 3.74; N, 2.60. Found: C, 26.58; H, 3.75; N, 2.58. IR (KBr, cm ${ }^{-1}$ ): 3439 (m), 2960 (w), 1641 (s), 1553 (s), 1534 (s), 1451 (s), 1395 (s), 1249 (w), 1116 (w), 816 (w) 780 (s), 732 (s).

$\left\{\left[\mathrm{Eu}_{2}(\mathrm{HL})_{2}\left(\mathrm{H}_{2} \mathrm{O}\right)_{4}\right] \cdot 2 \mathrm{Cl} \cdot 5 \mathrm{H}_{2} \mathrm{O}\right\}_{n}(2)$. Yield $62 \%$ (based on $\mathrm{Gd}$ ). Anal. calcd for $\mathrm{C}_{24} \mathrm{H}_{40} \mathrm{Cl}_{2} \mathrm{Eu}_{2} \mathrm{~N}_{2} \mathrm{O}_{21}$ (\%): C, 27.01; H, 3.78; N, 2.62. Found: C, 26.90; H, 3.81; N, 2.65. IR (KBr, $\left.\mathrm{cm}^{-1}\right): 3428(\mathrm{~m})$, 2981 (w), 1640 (s), 1552 (s), 1534 (s), 1449 (s), 1393 (s), 1249 (w), $1112(\mathrm{w}), 815$ (w) $781(\mathrm{~s}), 731(\mathrm{~s})$.

$\left\{\left[\mathrm{Tb}_{2}(\mathrm{HL})_{2}\left(\mathrm{H}_{2} \mathrm{O}\right)_{4}\right] \cdot 2 \mathrm{Cl} \cdot 5 \mathrm{H}_{2} \mathrm{O}\right\}_{n}(3)$. Yield $64 \%$ (based on $\mathrm{Tb}$ ). Anal. calcd for $\mathrm{C}_{24} \mathrm{H}_{40} \mathrm{Cl}_{2} \mathrm{~N}_{2} \mathrm{O}_{21} \mathrm{~Tb}_{2}$ (\%): C, 26.66; $\mathrm{H}, 3.73 ; \mathrm{N}$, 2.59. Found: C, 26.44; H, 3.75; N, 2.61. IR (KBr, $\left.\mathrm{cm}^{-1}\right): 3443(\mathrm{~m})$, 2952 (w), 1643 (s), 1548 (s), 1539 (s), 1457 (s), 1396 (s), 1250 (w), $1114(\mathrm{w}), 816$ (w) $780(\mathrm{~s}), 733(\mathrm{~s})$.

$\left\{\left[\mathrm{Dy}_{2}(\mathrm{HL})_{2}\left(\mathrm{H}_{2} \mathrm{O}\right)_{4}\right] \cdot 2 \mathrm{Cl} \cdot 5 \mathrm{H}_{2} \mathrm{O}\right\}_{n}(4)$. Yield $65 \%$ (based on Dy). Anal. calcd for $\mathrm{C}_{24} \mathrm{H}_{40} \mathrm{Cl}_{2} \mathrm{Dy}_{2} \mathrm{~N}_{2} \mathrm{O}_{21}$ (\%): C, 26.48; $\mathrm{H}, 3.70 ; \mathrm{N}$, 2.57. Found: C, 26.37; H, 3.73; N, 2.56. IR (KBr, $\left.\mathrm{cm}^{-1}\right): 3430(\mathrm{~m})$, 2952 (w), 1646 (s), 1550 (s), 1540 (s), 1456 (s), 1397 (s), 1249 (w), 1111 (w), 818 (w) 782 (s), $732(\mathrm{~s})$.

As for the isostructural mixed-lanthanide analogues, $\mathrm{Eu}^{3+} /$ $\mathrm{Tb}^{3+}$ or $\mathrm{Eu}^{3+} / \mathrm{Gd}^{3+} / \mathrm{Tb}^{3+}$ codoped compounds adopt the same methods as those mentioned above just by adding the corresponding $\mathrm{LnCl}_{3} \cdot 6 \mathrm{H}_{2} \mathrm{O}\left(\mathrm{Ln}^{3+}=\mathrm{Gd}^{3+}, \mathrm{Eu}^{3+}\right.$ or $\left.\mathrm{Tb}^{3+}\right)$ as the starting materials in different stoichiometric ratios. Their structure and purity were confirmed by PXRD (Fig. S4 $\dagger$ ), IR spectra (Fig. S1 $\dagger$ ), and elemental analyses (ICP) (Table S1†).

\section{Luminescence sensing experiments}

A ground sample $(10 \mathrm{mg})$ of the Tb-HMOF was dispersed in an aqueous solution $(3 \mathrm{~mL})$ of $\mathrm{M}\left(\mathrm{NO}_{3}\right)_{x}\left(\mathrm{M}^{x+}=\mathrm{Na}^{+}, \mathrm{K}^{+}, \mathrm{Ag}^{+}, \mathrm{Cd}^{2+}\right.$, $\mathrm{Ba}^{2+}, \mathrm{Mg}^{2+}, \mathrm{Mn}^{2+}, \mathrm{Ni}^{2+}, \mathrm{Zn}^{2+}, \mathrm{Cu}^{2+}, \mathrm{Co}^{2+}, \mathrm{Hg}^{2+}, \mathrm{Pb}^{2+}, \mathrm{Fe}^{3+}, \mathrm{Al}^{3+}$, or $\mathrm{Cr}^{3+}, 1 \times 10^{-3} \mathrm{~mol} \mathrm{~L}^{-1}$ ) which was ultrasonicated for $30 \mathrm{~min}$ at room temperature. The resulted mixtures were used for luminescent measurements.

\section{$\mathrm{X}$-ray structure determination}

On a Bruker APEX-II CCD diffractometer, single-crystal X-ray data of 1-4 were collected at 293(2) K using graphitemonochromated Mo $\mathrm{K} \alpha$ radiation $(\lambda=0.71073 \AA)$. Absorption corrections were applied by using the multiscan program SADABS. ${ }^{42}$ The structures were solved by direct methods and refined on $F^{2}$ full-matrix least-squares using the SHELXTL program package. ${ }^{\mathbf{3}, \mathbf{4 4}}$ All of the non-hydrogen atoms were refined with anisotropic displacement parameters during the 
final cycles. The $\mathrm{H}$ atoms attached to $\mathrm{C}$ were generated geometrically while the $\mathrm{H}$ atoms attached to $\mathrm{O}$ and $\mathrm{N}$ were located from different Fourier maps and treated as idealized contributions. Unluckily, the $\mathrm{H}$ atoms of some water molecules were not added owing to not suitable Fourier maps being picked up. Notably, the precision of the $\mathrm{C}-\mathrm{C}$ bonds of $\mathbf{2 - 4}$ is slightly low, which perhaps results from the weak diffractions owing to the bad quality and small sizes of the single crystals and/or from the effects of heavy Ln atoms whose strong diffraction signals affect the accurate detection of lighter atoms C. Further attempts to get suitable single crystals by different methods as well as the recollecting crystal data at a lower temperature were of fail. The crystal data were summarized in Table 1 , and the selected bond distances were given in Table $\mathrm{S} 2 . \dagger$

\section{Results and discussion}

\section{Synthesis and general characterization of compounds}

The isostructural Ln-HMOFs including the mixed-lanthanide species were solvothermally synthesized at $120{ }^{\circ} \mathrm{C}$ using the corresponding $\mathrm{LnCl}_{3} \cdot 6 \mathrm{H}_{2} \mathrm{O}$ and the chiral ligand $\mathrm{H}_{3} \mathrm{~L}$ in a mixed solvent of deionized $\mathrm{H}_{2} \mathrm{O}$ and acetonitrile. The crystalline products are air-stable and insoluble in water or any common organic solvents.

The chemical formulas of single-lanthanide compounds 1-4 have been confirmed by satisfactory elemental analysis and single-crystal X-ray diffraction. In the IR spectra of 1-4, the strong and broad absorption bands in a range of 3400$3500 \mathrm{~cm}^{-1}$ indicates the presence of $\nu_{\mathrm{N}-\mathrm{H}}$ and the $\nu_{\mathrm{O}-\mathrm{H}}$ stretching frequencies of amino groups and water molecules, respectively. Four complexes exhibit strong characteristic absorptions around $1534-1646 \mathrm{~cm}^{-1}$ for $\nu_{\text {as }}\left(-\mathrm{COO}^{-}\right)$and $1393-$ $1457 \mathrm{~cm}^{-1}$ for $\nu_{\mathrm{s}}\left(-\mathrm{COO}^{-}\right)$, respectively. However, no strong characteristic absorptions around $1700 \mathrm{~cm}^{-1}$ for $(-\mathrm{COOH})$ were observed, being in agreement with the single-crystal X-ray diffraction analysis results that all carboxyl groups of ligand $\mathrm{H}_{3} \mathrm{~L}$ in compounds 1-4 were deprotonated. The accurate molar ratios of the individual lanthanide elements in the mixed- lanthanide compounds have been determined by inductively coupled lasma (ICP) spectroscopy (Table S1†), being well consistent with the corresponding ratios in the starting mixture. The phase purities and isostructuralism of all the assynthesized Ln-HMOFs have been verified by powder X-ray diffraction (PXRD) measurements. Clearly, the experimental PXRD patterns of single-lanthanide compounds 1-4 are very similar to each other and match well with those simulated, indicating the phase purities and isostructuralism of those polycrystalline samples (Fig. S3†). Meanwhile, the observed PXRD patterns of all the bi- and tri-metallic doped samples are in conformity to the simulated pattern of $\mathbf{1}$ (Fig. S4†), demonstrating that they are isostructural with single-lanthanide compounds 1-4. Single-lanthanide compounds 1-4 all experience a very similar three-stepped thermal decomposition behavior revealed by TGA (Fig. S2 $\dagger$ ). The first weight loss corresponds to the removal of five lattice water molecules (calcd. $8.36 \%$, obsed. $7.70 \%$ for 1; calcd. $8.44 \%$, obsed. $7.60 \%$ for 2 ; calcd. $8.33 \%$, obsed. $8.23 \%$ for 3 ; calcd. $8.28 \%$, obsed. $7.65 \%$ for 4 ) before $130,135,150$, and $155^{\circ} \mathrm{C}$, respectively. The second weight loss occurs in a temperature range of $155-230^{\circ} \mathrm{C}$, being attributable to the release of four coordinated water molecules (calcd. 6.68\%, obsed. $6.60 \%$ for 1 ; calcd. $6.75 \%$, obsed. $6.62 \%$ for 2 ; calcd. $6.66 \%$, obsed. $6.10 \%$ for 3 ; calcd. $6.62 \%$, obsed. $6.07 \%$ for 4 ). The removal of the organic components (calcd. $51.33 \%$, obsed. $48.65 \%$ for 1 ; calcd. $51.84 \%$, obsed. $48.02 \%$ for 2 ; calcd. $51.17 \%$, obsed. $48.84 \%$ for 3 ; calcd. $50.83 \%$, obsed. $49.45 \%$ for 4 ) occurred in a temperature range of $300-700{ }^{\circ} \mathrm{C}$. The final residue for each complex corresponds to the formation of the respective lanthanide oxide. In addition, the thermal decomposition behavior of the trimetallic doped sample has been also investigated as a representative of the mixed-lanthanide species, and the result shows that its thermal decomposition behavior (weight loss and decomposition temperature) is surprisingly similar to that of all singlelanthanide compounds (Fig. S2 $\dagger$ ). The TGA results show that these single- and mixed-lanthanide frameworks have higher thermal stabilities being suitable for potential applications in

Table 1 Crystal data and structure refinement for 1-4

$\begin{array}{ll}\text { Compounds } & \mathbf{1} \\ \text { Formula } & \mathrm{C}_{24} \mathrm{H}_{40} \mathrm{Cl}_{2} \mathrm{Gd}_{2} \mathrm{~N}_{2} \mathrm{O}_{21} \\ \text { Temp }(\mathrm{K}) & 293(2) \\ \text { Formula weight } & 1077.98 \\ \text { Crystal system } & \text { Triclinic } \\ \text { Space group } & P 1 \\ a(\AA) & 9.6682(6) \\ b(\AA) & 10.0302(6) \\ c(\AA) & 10.9110(7) \\ \alpha /^{\circ} & 104.893(2) \\ \beta /{ }^{\circ} & 93.675(2) \\ \gamma /^{\circ} & 110.003(2) \\ V\left(\AA^{3}\right) & 947.30(10) \\ \left.Z, \rho_{\text {calcd }}(\mathrm{g} \mathrm{cm})^{-3}\right) & 1,1.890 \\ \text { GOF } & 1.061 \\ \text { Flack parameter } & 0.195(8) \\ R 1, w R 2(I>2 \sigma(I)) & 0.0164,0.0427 \\ \text { Largest diff. peak and hole } & 0.668,-0.517\end{array}$

Largest diff. peak and hole

2
$\mathrm{C}_{24} \mathrm{H}_{40} \mathrm{Cl}_{2} \mathrm{Eu}_{2} \mathrm{~N}_{2} \mathrm{O}_{21}$
$293(2)$
1067.40
Triclinic
$P 1$
$9.6686(6)$
$10.0202(4)$
$10.8727(4)$
$104.824(3)$
$93.710(5)$
$109.569(5)$
$946.31(8)$
$1,1.873$
1.052
$0.20(3)$
$0.0603,0.1298$
$3.370,-2.031$

3
$\mathrm{C}_{24} \mathrm{H}_{40} \mathrm{Cl}_{2} \mathrm{~Tb}_{2} \mathrm{~N}_{2} \mathrm{O}_{21}$
$293(2)$
1081.32
Triclinic
$P 1$
$9.6763(4)$
$10.0338(4)$
$10.9853(5)$
$105.072(3)$
$93.691(3)$
$110.107(4)$
$953.10(7)$
$1,1.884$
1.060
$0.25(2)$
$0.0415,0.0804$
$0.994,-0.778$

4
$\mathrm{C}_{24} \mathrm{H}_{40} \mathrm{Cl}_{2} \mathrm{Dy}_{2} \mathrm{~N}_{2} \mathrm{O}_{21}$
$293(2)$
1088.48
Triclinic
$P 1$
$9.6947(4)$
$10.0533(5)$
$11.0032(7)$
$105.039(5)$
$93.823(4)$
$110.052(4)$
$958.48(9)$
$1,1.886$
1.051
$0.22(2)$
$0.0467,0.0840$
$1.159,-0.985$


solid-state luminescence materials, and again confirm the number of lattice and coordinated water molecules in their chemical formulas.

\section{Crystal structure descriptions}

Structures of $\left\{\left[\mathrm{Ln}_{2}(\mathrm{HL})_{2}\left(\mathrm{H}_{2} \mathrm{O}\right)_{4}\right] \cdot 2 \mathrm{Cl} \cdot 5 \mathrm{H}_{2} \mathrm{O}\right\}_{n}[\mathrm{Ln}=\mathrm{Gd}(1), \mathbf{E u}$ (2), Tb (3) and Dy (4)]. Four single-lanthanide compounds 1-4 were determined crystallographically. They are isostructural with the same chiral space group $P 1$, and feature the dinuclear cluster-based 2D networks. Though the check results using PLATON suggest that there is a possibly higher pseudosymmetry $P \overline{1}$ in their structural models, this can be due to the pseudotranslation symmetry of heavy Ln atoms. ${ }^{45,46}$ Their chirality was further confirmed by the solid-state CD spectra (vide infra). As a representative case, only the crystal structure of $\mathbf{1}$ is herein discussed in detailed. The asymmetric unit of $\mathbf{1}$ consists of two (HL) ${ }^{2-}$ ligands, two independent $\mathrm{Gd}^{3+}$ ions, four coordinated water molecules, five lattice water molecules, and two free $\mathrm{Cl}^{-}$. Gd1 and $\mathrm{Gd} 2$ are nine-coordinated by seven $\mathrm{O}$ atoms from two chelating carboxylates and three bridging carboxylates of five different $(\mathrm{HL})^{2-}$ ligands and two $\mathrm{O}$ atoms from water molecules, respectively, forming distorted singlecapped square antiprism $\left(C_{4 \mathrm{v}}\right)$ polyhedron configurations (Fig. 1a). The Gd-O bond lengths vary from 2.310(8) $\AA$ to 2.925(8) A, which corresponds to those reported for other lanthanide-oxygen donor complexes, ${ }^{47}$ and the $\mathrm{O}-\mathrm{Gd}-\mathrm{O}$ angles range from $47.4(2)$ to $148.2(3)^{\circ}$. Every $\mathrm{H}_{3} \mathrm{~L}$ ligand in 1, with its three carboxyls being completely deprotonated and meanwhile its amino group being protonated, exists in a zwitterionic form of $(\mathrm{HL})^{2-}$ as observed in its Pb-HMOF. ${ }^{38}$ Interestingly, the three carboxylate groups of $(\mathrm{HL})^{2-}$ adopt three different coordination modes, namely, chelating fashion $\mu_{1}-\eta^{1}: \eta^{1}$, chelating and

(a)

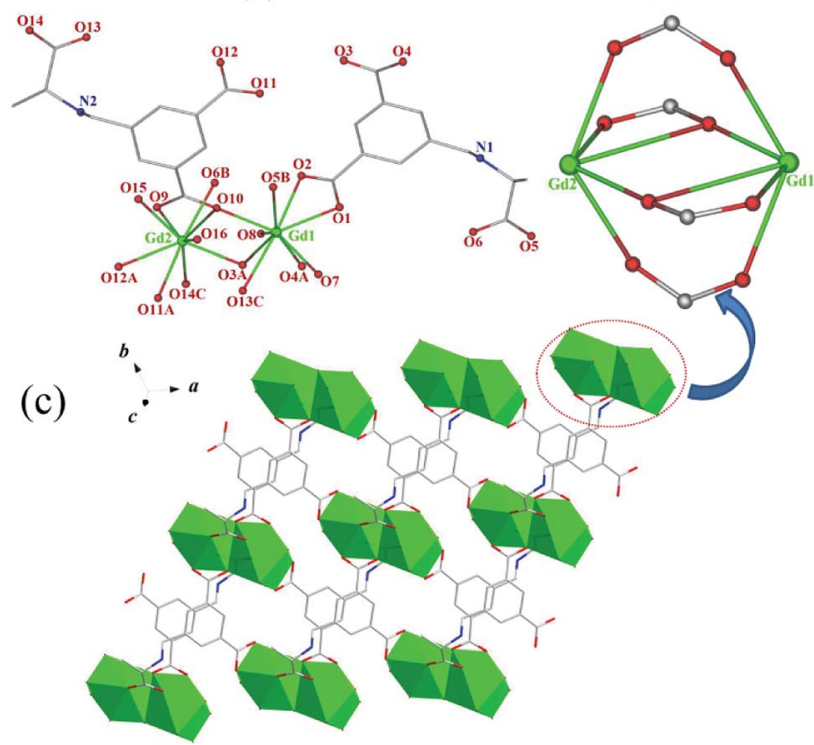

Fig. 1 (a) Coordination geometries of $\mathrm{Gd}^{3+}$ in 1; (b) binuclear cluster $\left[\mathrm{Gd}_{2}(\mathrm{COO})_{4}\right]$ unit; (c) wave-like homochiral layer structure of 1 based on binuclear cluster units $\left[\mathrm{Gd}_{2}(\mathrm{COO})_{4}\right]$ and zwitterionic $(\mathrm{HL})^{2-}$ linkers. Symmetry code: (A) $x, 1+y, z$; (B) $-1+x, y, z$; (C) $1+x, 1+y, z$. bridging fashion $\mu_{2}-\eta^{2}: \eta^{1}$, and bridging fashion $\mu_{2}-\eta^{1}: \eta^{1}$, unlike to those found in its transition metal frameworks. ${ }^{38}$ Consequently, ligand (HL) ${ }^{2-}$ acts as a $\kappa_{7}$-linker to connect five $\mathrm{Gd}^{3+}$ ions.

Notably, the two independent $\mathrm{Gd}^{3+}$ ions are connected by four carboxylate groups from four $(\mathrm{HL})^{2-}$ ligands to form a binuclear cluster $\left[\mathrm{Gd}_{2}(\mathrm{COO})_{4}\right]$ (Fig. $\left.1 \mathrm{~b}\right)$, which is connected by $(\mathrm{HL})^{2-}$ to produce a wave-like homochiral layer paralleling to $a b$ plane (Fig. 1c). In the layer, each $(\mathrm{HL})^{2-}$ ligand bonds three $\left[\mathrm{Gd}_{2}(\mathrm{COO})_{4}\right]$ units. Topologically, the $(\mathrm{HL})^{2-}$ ligand and $\left[\mathrm{Gd}_{2}(\mathrm{COO})_{4}\right]$ unit can be considered as 3- and 6-connected nodes, respectively. Thus, the whole framework of 1 can be described as a $(3,6)$-connected kgd net with point (Schläfli) symbol of $\left(4^{3}\right)_{2}\left(4^{6} \cdot 6^{6} \cdot 8^{3}\right)$ [Fig. 2]. Those layers stack up along $c$ axis with their chiral aminopropionate groups arraying up and down. Moreover, every protonated amino group of $(\mathrm{HL})^{2-}$ ligand hydrogen-bonds two independent chloride anions (Cl1 and $\mathrm{Cl} 2$ ) which are further hydrogen-bonded by another amino group from the adjacent layer, and in such a way it results in an interesting 3D porous homochiral pillared-layer supramolecular framework with lattice water molecules in apertures when regarded the hydrogen-bonded $\left(\mathrm{N}_{2} \mathrm{Cl}_{2}\right)$ rings as pillars (Fig. 3).

It should be mentioned that with the radium decrease of $\mathrm{Ln}$ atoms the $\kappa_{7}$-linker $(\mathrm{HL})^{2-}$ in 1 and 2 becomes the $\kappa_{6}$-linker $(\mathrm{HL})^{2-}$ in 3 and 4 owing to the chelating and bridging fashion $\mu_{2}$ $-\eta^{2}: \eta^{1}$ of the carboxylate becoming the bridging fashion $\mu_{2}-$ $\eta^{1}: \eta^{1}$ (Scheme 1, Fig. S5-S7†). As a result, both $\mathrm{Tb}^{3+}$ in 3 and $\mathrm{Dy}^{3+}$ in $\mathbf{4}$ adopt eight-coordinated slightly distorted square antiprism $\left(C_{4 \mathrm{v}}\right)$ polyhedron configurations (Fig. S6-S7†). In their binuclear clusters $\left[\mathrm{Tb}_{2}(\mathrm{COO})_{4}\right]$ and $\left[\mathrm{Dy}_{2}(\mathrm{COO})_{4}\right]$, the bridging model between the two metal centers is slightly different from that found in the binuclear clusters $\left[\mathrm{Gd}_{2}(\mathrm{COO})_{4}\right]$ and $\left[\mathrm{Eu}_{2}(\mathrm{COO})_{4}\right]$ (Fig. 1 and S5-S7†).

\section{Solid-state circular dichroism (CD) studies}

To further demonstrate their homochirality, solid-state CD spectra of 1-4 have been measured with $\mathrm{KBr}$ pellets (Fig. 4). In

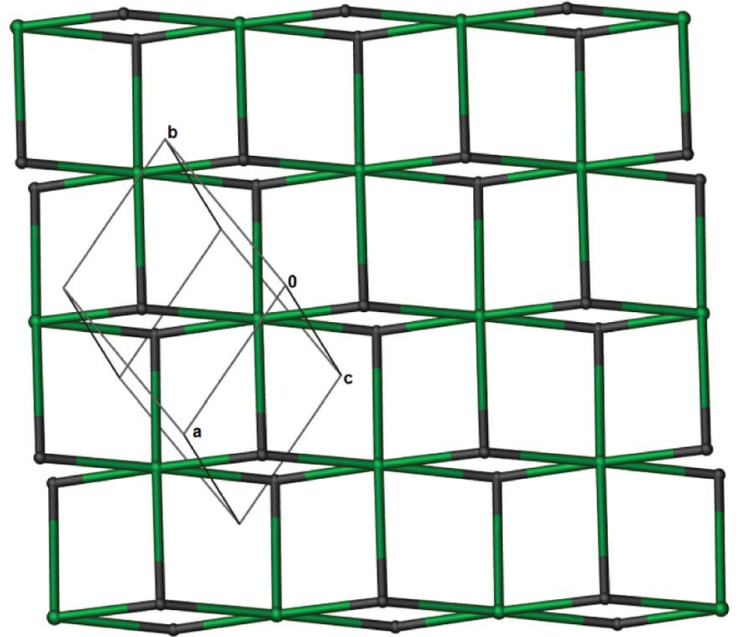

Fig. 2 Schematic representation of 2D $(3,6)$-connected kgd topology of 1 . 


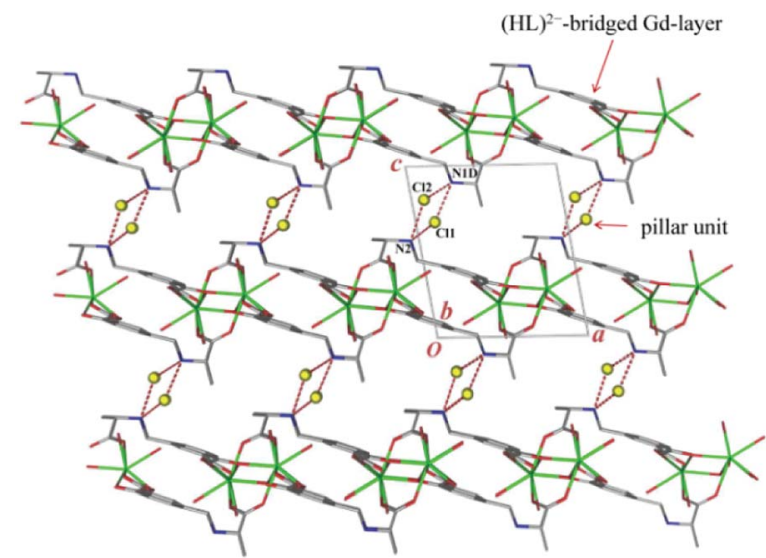

Fig. 3 View of interesting 3D porous homochiral pillared-layer supramolecular framework of 1 , regarding the hydrogen-bonded $\left(\mathrm{N}_{2} \mathrm{Cl}_{2}\right)$ rings as pillars (N2 $\cdots \mathrm{Cl} 1=3.209(10) \AA, \mathrm{N} 2 \cdots \mathrm{Cl} 2=3.071(9) \AA, \mathrm{N} 1 \mathrm{D} \cdots \mathrm{Cl} 1=$ 3.129(9) $\AA$, N1D $\cdots C l 2=3.210(10) \AA$; lattice water molecules in apertures were omitted for clarity). Symmetry code: (D) $-1+x, y, 1+z$.

their CD spectra, obvious chiroptical signals have been observed in the ultra band of 200-400 nm, which perhaps originate in the $\pi \rightarrow \pi^{*}$ transitions of $(\mathrm{HL})^{2-}$ ligand. For 1 , positive Cotton effects center at 203 and $224 \mathrm{~nm}$, and negative Cotton effects center at 218 and $295 \mathrm{~nm}$. For 2, positive Cotton effects center at 205, 223 and $240 \mathrm{~nm}$, and negative Cotton effects center at 217 and $234 \mathrm{~nm}$. The CD spectrum of 3 exhibits positive Cotton effects centered at 203 and $240 \mathrm{~nm}$, and negative Cotton effects centered at 220 and $235 \mathrm{~nm}$. As for 4, it displays positive Cotton effects centered at 203, 242 and $270 \mathrm{~nm}$, and negative Cotton effects centered at 219 and $249 \mathrm{~nm}$. From the above results, the inherent chirality of $\mathrm{H}_{3} \mathrm{~L}$ ligand was transmitted to the resulting Ln-HMOFs.

\section{Photoluminescence properties}

The lanthanide MOFs usually show excellent luminescent properties. Hence, the photoluminescence of complexes 1-4 and their lifetimes were investigated at room temperature. The excitation spectra for free ligand $\mathrm{H}_{3} \mathrm{~L}$ and complexes 1-4 are given in Fig. S8-S9. $\uparrow$ Upon excitation at $310 \mathrm{~nm}$, the free ligand $\mathrm{H}_{3} \mathrm{~L}$ exhibits a broad fluorescent emission centered at $369 \mathrm{~nm}$

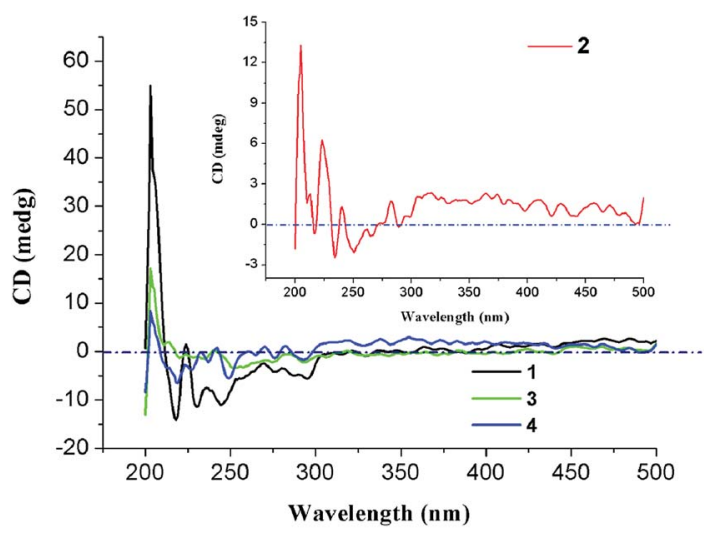

Fig. 4 Solid-state CD spectra of compounds 1-4.
(Fig. 5a), maybe attributing to intraligand $\pi^{*} \rightarrow \pi$ charge transfer. Complex 1 presents a broad blue emission centered at $443 \mathrm{~nm}\left(\lambda_{\mathrm{ex}}=365 \mathrm{~nm}\right)$ [Fig. 5b], also assignable to the intraligand charge transition of $(\mathrm{HL})^{2-}$ ligand. Compared with the emission of free ligand $\mathrm{H}_{3} \mathrm{~L}$, the emission peak of 1 red-shifts by $74 \mathrm{~nm}$, indicating obvious influence upon the HOMO and LUMO levels of the coordinated ligand (HL) ${ }^{2-}$ as well as the energy transitions between them owing to the coordination of $\mathrm{Gd}^{3+}$ ions. This phenomenon is similar to the previously reported. ${ }^{48}$ The CIE color coordinate is $(0.198,0.214)$ for 1 . Upon excitation at $395 \mathrm{~nm}, 2$ emits the bright characteristic red color of $\mathrm{Eu}^{3+}$ ions with the CIE color coordinate of $(0.587,0.316)$. The emission peaks at 593, 615, 653 and $701 \mathrm{~nm}$ are assigned to ${ }^{5} D_{0}$ $\rightarrow{ }^{7} F_{J}(J=1,2,3,4)$ transitions of $\mathrm{Eu}^{3+}$ ions, respectively, without the emission peak corresponding to ${ }^{5} D_{0} \rightarrow{ }^{7} F_{0}$ transition being observed (Fig. 5c). The electric dipole transition ${ }^{5} D_{0}$ $\rightarrow{ }^{7} F_{2}$ dominates the red color emission while the ${ }^{5} D_{0} \rightarrow{ }^{7} F_{1}$ transition is insensitive to the site symmetry as a magnetic dipole. For 2 the intensity ratio of $I\left({ }^{5} D_{0} \rightarrow{ }^{7} F_{2}\right) / I\left(\left({ }^{5} D_{0} \rightarrow{ }^{7} F_{1}\right)\right.$ is about 5.28, indicating that the $\mathrm{Eu}^{3+}$ ions locate at a low symmetric coordination environment without an inversion center. ${ }^{34,37}$ This result is in agreement with the crystal structural analysis result that every $\mathrm{Eu}^{3+}$ ion adopts a distorted noncentral single-capped square antiprism $\left(C_{4 v}\right)$ polyhedron configurations (Fig. S6†). Upon excitation at $352 \mathrm{~nm}$, complex 3 exhibits characteristic $\mathrm{Tb}^{3+}$ emissions at 490, 545, 586 and $622 \mathrm{~nm}$, which can be attributed to ${ }^{5} D_{4} \rightarrow{ }^{7} F_{J}(J=6,5,4,3)$ transitions, respectively (Fig. 5d). The most intense transition of ${ }^{5} D_{4} \rightarrow{ }^{7} F_{5}$ leads to strong green luminescence of the crystal sample, which makes 3 become a promising green emitting phosphors with the CIE color coordinate of $(0.278,0.541)$.

It is worth noting that the ligand-based emission in the fluorescence spectra of compounds 2 and $\mathbf{3}$ was not observed, indicating effective energy transfer from ligand $(\mathrm{HL})^{2-}$ to the lanthanide centers via "antenna effect". The luminescence decay curves of 1-3 were obtained in the solid state at room
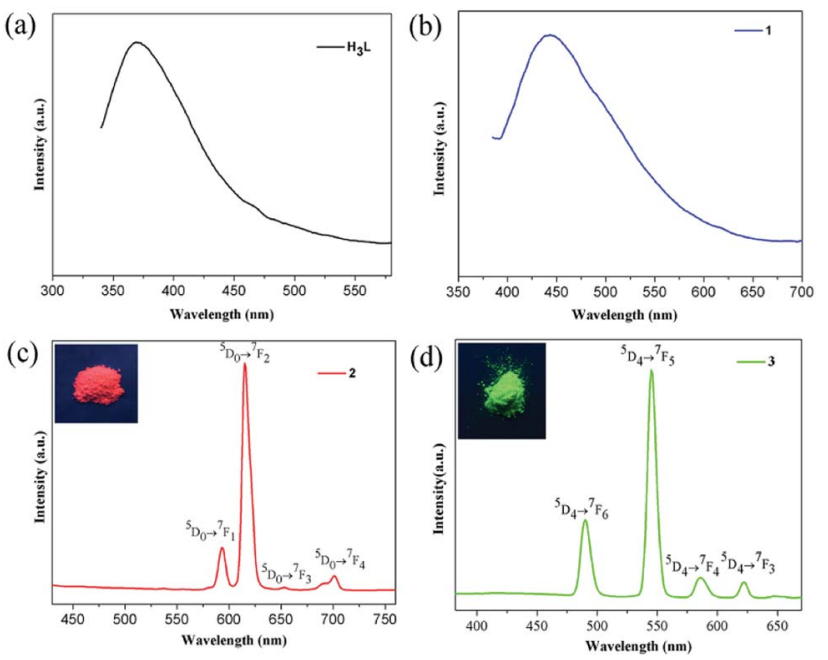

Fig. 5 Solid-state emission spectra of free ligand $\mathrm{H}_{3} \mathrm{~L}$ (a), 1 (b), 2 (c), and 3 (d) at room temperature. The insets show the corresponding luminescence pictures under UV-light irradiation at $365 \mathrm{~nm}$. 
temperature (Fig. S10-S12 $\dagger$ ). Complexes 1-3 display the singleexponential luminescent decay with the lifetimes of 9.88, 352.95 and $826.26 \mu \mathrm{s}$, respectively, and the quantum yields $\Phi_{\text {overall }}$ are $3.9 \%$ for complex 2 and $5.2 \%$ for complex 3, respectively. When excited at $365 \mathrm{~nm}$ at room temperature, compound 4 displays blue photoluminescence mainly originating from the intraligand charge transition of $(\mathrm{HL})^{2-}$ ligand (Fig. S9†).

\section{Tuning of luminescent color for bimetallic doped Eu/Tb-HMOFs}

The isostructuralism of the resulting Ln-HMOFs 1-4 gives a chance to synthesize heterometallic frameworks by codoping. A series of bimetallic doped Eu/Tb-HMOFs $\left[\left(\mathrm{Eu}_{x} \mathrm{~Tb}_{1-x}\right)_{2}(-\right.$ $\left.\mathrm{HL})_{2}\left(\mathrm{H}_{2} \mathrm{O}\right)_{4}\right] \cdot 2 \mathrm{Cl} \cdot 5 \mathrm{H}_{2} \mathrm{O}$ were successfully obtained by adjusting different molar ratios of $\mathrm{Eu}^{3+}$ and $\mathrm{Tb}^{3+}$ reactants, and the molar ratio of $\mathrm{Eu}^{3+}$ and $\mathrm{Tb}^{3+}$ ions was determined by means of ICP spectroscopy (Table S1†).

As shown in Fig. 6a, the bimetallic doped Eu/Tb-HMOFs exhibit the dual emissions of $\mathrm{Eu}^{3+}$ and $\mathrm{Tb}^{3+}$ ions in their luminescent spectra when excited at $370 \mathrm{~nm}$. With the increase of $\mathrm{Eu}^{3+} / \mathrm{Tb}^{3+}$ molar ratios, the emission intensity of $\mathrm{Tb}^{3+}$ at

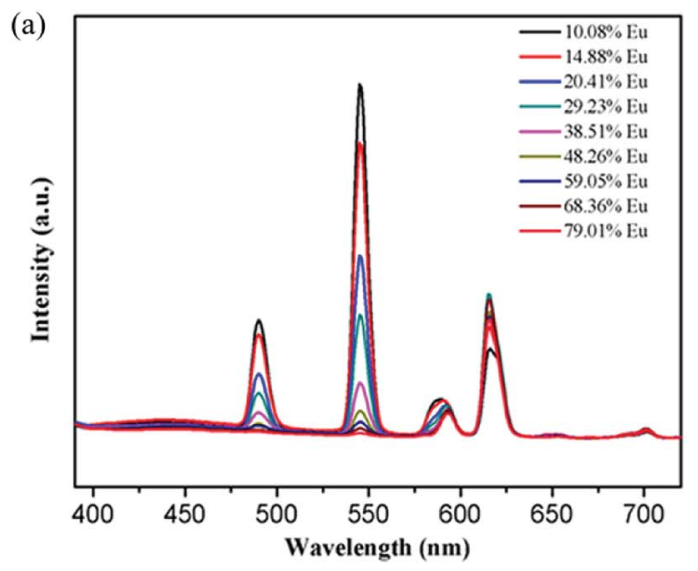

(b)

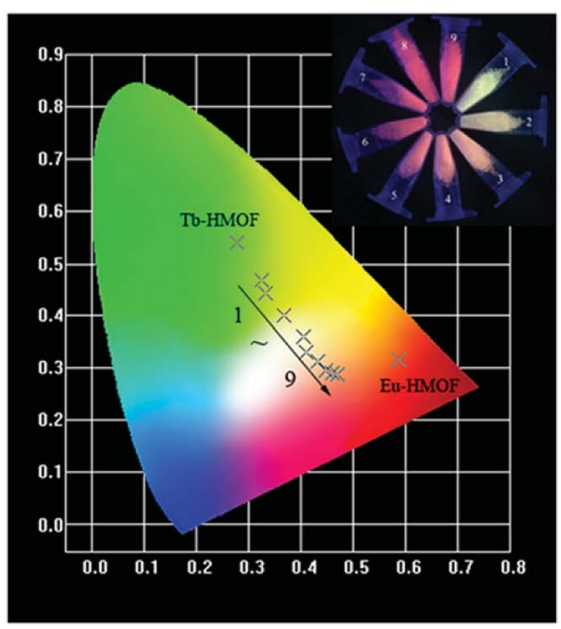

Fig. 6 (a) Solid-state emission spectra of the bimetallic Eu/Tb-HMOFs $\left[\left(\mathrm{Eu}_{x} \mathrm{~Tb}_{1-x}\right)_{2}(\mathrm{HL})_{2}\left(\mathrm{H}_{2} \mathrm{O}\right)_{4}\right] \cdot 2 \mathrm{Cl} \cdot 5 \mathrm{H}_{2} \mathrm{O}$ when excited at $370 \mathrm{~nm}(x=$ 10.08-79.01 mol\%); (b) the CIE chromaticity diagram for Eu-HMOF (2), Tb-HMOF (3), and the bimetallic doped Eu/Tb-HMOFs. The inset shows the luminescence picture of the bimetallic doped Eu/TbHMOFs under UV-light irradiation at $365 \mathrm{~nm}$.
$545 \mathrm{~nm}\left({ }^{5} D_{4} \rightarrow{ }^{7} F_{5}\right)$ decreases monotonically, while that of $\mathrm{Eu}^{3+}$ at $615 \mathrm{~nm}\left({ }^{5} D_{0} \rightarrow{ }^{7} F_{2}\right)$ increases stepwise to reach a maximum when the mole fraction of $\mathrm{Eu}^{3+}$ is $29.23 \mathrm{~mol} \%$, and then decreases slightly due to the concentration quenching effect. ${ }^{\mathbf{1 7 , 4 9}}$ The observation suggests the enhanced probability of energy transfer from $\mathrm{Tb}^{3+}$ to $\mathrm{Eu}^{3+}$ with the increase of $\mathrm{Eu}^{3+}$ concentration..$^{15,17,19,49}$ Furthermore, the fluorescence decay of the ${ }^{5} D_{4}$ $\rightarrow{ }^{7} F_{5}$ transition of $\mathrm{Tb}^{3+}$ and the ${ }^{5} D_{0} \rightarrow{ }^{7} F_{2}$ transition of $\mathrm{Eu}^{3+}$ in the bimetallic doped samples of $\left[\left(\mathrm{Eu}_{x} \mathrm{~Tb}_{1-x}\right)_{2}(\mathrm{HL})_{2}\left(\mathrm{H}_{2} \mathrm{O}\right)_{4}\right]$. $2 \mathrm{Cl} \cdot 5 \mathrm{H}_{2} \mathrm{O}(x=14.88-38.51 \mathrm{~mol} \%)$ was also investigated. The results show that with the increase of $\mathrm{Eu}^{3+}$ doping, the obtained effective lifetime of $\mathrm{Tb}^{3+}$ shortens while that of $\mathrm{Eu}^{3+}$ basically increases (Table S3 and Fig. S13†), which indicates that the concentration of doped $\mathrm{Eu}^{3+}$ significantly changes the fluorescent dynamics of $\mathrm{Tb}^{3+}$ and further confirm an efficient energy transfer from $\mathrm{Tb}^{3+}$ to $\mathrm{Eu}^{3+}$. Notably, the lifetime of $\mathrm{Eu}^{3+}$ also reaches a maximum when the mole fraction of $\mathrm{Eu}^{3+}$ is $29.23 \mathrm{~mol} \%$, and then shortens slightly with the further increase of $\mathrm{Eu}^{3+}$ doping, reflecting the above mentioned concentration quenching effect. In addition, the observed energy transfer between $\mathrm{Tb}^{3+}$ and $\mathrm{Eu}^{3+}$ also confirms that the assynthesized bimetallic doped compounds are single-phase coordination polymers where $\mathrm{Eu}^{3+}$ has been successfully incorporated into the lattice of 3 because the energy transfer could not occur in a mixture of separated phases.

Interestingly, the bimetallic doped Eu/Tb-HMOFs present a wide range of visible emission colors such as green, yellow, orange, orange-red, and red under UV-light irradiation at $365 \mathrm{~nm}$ (Fig. 6b), indicating that the luminescent colors of the bimetallic doped Eu/Tb-HMOFs $\left[\left(\mathrm{Eu}_{x} \mathrm{~Tb}_{1-x}\right)_{2}(\mathrm{HL})_{2}\left(\mathrm{H}_{2} \mathrm{O}\right)_{4}\right]$. $2 \mathrm{Cl} \cdot 5 \mathrm{H}_{2} \mathrm{O}$ can be systematically modulated through adjusting different mole fractions of $\mathrm{Tb}^{3+}$ and $\mathrm{Eu}^{3+}$. At the same time, with the change of the concentration of the doping $\mathrm{Eu}^{3+}$ in the heterometallic frameworks, the corresponding CIE chromaticity coordinates change from $(0.325,0.468)$ to $(0.470,0.287)$ (Fig. $6 \mathrm{~b}$ and Table S4†).

\section{WLED for trimetallic doped Eu/Gd/Tb-HMOF}

Being considered as fourth-generation light sources, whitelight-emitting diodes (WLEDs) have greatly attracted current interest owing extensive applications in displays and lighting. Isostructural compounds 1, 2 and 3, as observed above, exhibit blue, red and green primary colors, respectively, which is expected that white light emission could be obtained by the doping of $\mathrm{Eu}^{3+}$ and $\mathrm{Tb}^{3+}$ ions into the $\mathrm{Gd}^{3+}$ compound $\mathbf{1}$. Indeed, the emission output of Eu/Gd/Tb-HMOFs can be controlled precisely through the compositional adjustment of the three metal ions. By optimizing the molar ratio of $\mathrm{Eu}^{3+}, \mathrm{Gd}^{3+}$ and $\mathrm{Tb}^{3+}$ ions, the trimetallic doped Eu/Gd/Tb-HMOF $\left[\left(\mathrm{Eu}_{0.1388} \mathrm{Gd}_{0.6108} \mathrm{~Tb}_{0.2504}\right)_{2}(\mathrm{HL})_{2}\left(\mathrm{H}_{2} \mathrm{O}\right)_{4}\right] \cdot 2 \mathrm{Cl} \cdot 5 \mathrm{H}_{2} \mathrm{O}$ was synthesized successfully. Upon excitation at $370 \mathrm{~nm}$, this threecomponent compound simultaneously shows the triple emissions originating from the emissions of $\mathrm{Eu}^{3+}, \mathrm{Tb}^{3+}$ and the coordinated ligand (HL) ${ }^{2-}$, respectively (Fig. 7a), and its CIE color coordinate is $(0.285,0.298)$. Furthermore, we have systematically studied the subtle effects of excitation 

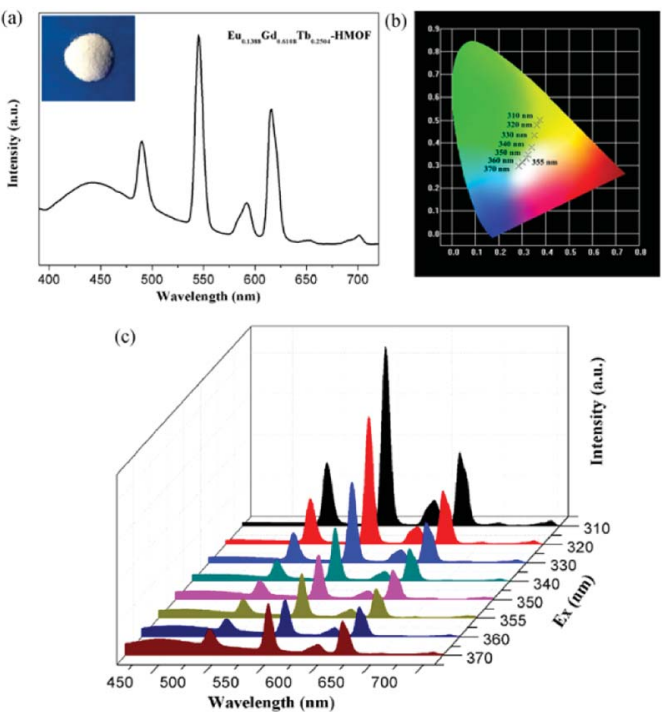

Fig. 7 (a) Solid-state emission spectra of the trimetallic doped Eu/Gd/ $\mathrm{Tb}-\mathrm{HMOF} \quad\left[\left(\mathrm{Eu}_{0.1388} \mathrm{Gd}_{0.6108} \mathrm{~Tb}_{0.2504}\right)_{2}(\mathrm{HL})_{2}\left(\mathrm{H}_{2} \mathrm{O}\right)_{4}\right] \cdot 2 \mathrm{Cl} \cdot 5 \mathrm{H}_{2} \mathrm{O}$ when excited at $370 \mathrm{~nm}$ (the inset shows the corresponding luminescence picture under UV-light irradiation at $365 \mathrm{~nm}$ ); (b) the CIE-1931 chromaticity diagram for the trimetallic doped $\mathrm{Eu} / \mathrm{Gd} / \mathrm{Tb}-\mathrm{HMOF}$ with excitation wavelengths varying from 310 to $370 \mathrm{~nm}$; (c) solid-state emission spectra of the trimetallic doped Eu/Gd/Tb-HMOF with excitation wavelengths varying from 310 to $370 \mathrm{~nm}$.

wavelength changes upon the luminescent color of the trimetallic doped $\mathrm{Eu} / \mathrm{Gd} / \mathrm{Tb}-\mathrm{HMOF}$ (Fig. $7 \mathrm{~b}$ and c). As shown in Fig. $6 \mathrm{~b}$, when the excitation wavelength is controlled from 310 to $370 \mathrm{~nm}$, the emission color of the trimetallic doped $\mathrm{Eu} / \mathrm{Gd} /$ Tb-HMOF changes from yellow to white (CIE coordinates in Table S5 $†$ ). The white emission of the trimetallic doped Eu/Gd/ Tb-HMOF has been obtained upon excitation at $355 \mathrm{~nm}$ [the CIE color coordinate is $(0.317,0.331)$; the average lifetime values for $\mathrm{Tb}^{3+}$ and $\mathrm{Eu}^{3+}$ ions are 753.59 and $473.03 \mu \mathrm{s}$, respectively (Fig. S14 $\dagger$ ), and the overall quantum yield is about $4.2 \%$,], which is very close to that of pure white light $(0.333,0.333)$ according to $1931 \mathrm{CIE}$ coordinate diagram. The colour rendering index (CRI) and corresponding colour temperature (CCT) are 82 and $6261 \mathrm{~K}$, respectively, which satisfy the necessary conditions for high quality white light-emitting materials (CRI above 80 and CCT in the range of 2500-6500 K). Although the quantum yield value is smaller than that of several recent trimetallic doped 3D $\mathrm{Eu} / \mathrm{Gd} / \mathrm{Tb}-\mathrm{MOFs},{ }^{15,19}$ studies on $2 \mathrm{D}$ Ln-HMOFs as multicolor luminescence materials are fewer at present.

\section{Luminescent sensing of metal ions}

To research the potential of Tb-HMOF for sensing of metal ions, the ground samples of the as-synthesized Tb-HMOF were dispersed in aqueous solutions of $\mathrm{M}\left(\mathrm{NO}_{3}\right)_{x}\left(\mathrm{M}^{x+}=\mathrm{Na}^{+}, \mathrm{K}^{+}, \mathrm{Ag}^{+}\right.$, $\mathrm{Cd}^{2+}, \mathrm{Ba}^{2+}, \mathrm{Mg}^{2+}, \mathrm{Mn}^{2+}, \mathrm{Ni}^{2+}, \mathrm{Zn}^{2+}, \mathrm{Cu}^{2+}, \mathrm{Co}^{2+}, \mathrm{Hg}^{2+}, \mathrm{Pb}^{2+}, \mathrm{Fe}^{3+}$, $\mathrm{Al}^{3+}$, and $\mathrm{Cr}^{3+}$ ), and handled with ultrasonication treatment for $30 \mathrm{~min}$ to form a metal-ion-incorporated Tb-HMOF suspension whose fluorescent measurements were carried out at room temperature upon excited at $\lambda_{\text {ex }}=352 \mathrm{~nm}$. As shown in Fig. 8, the incorporated various metal ions exhibit different influences
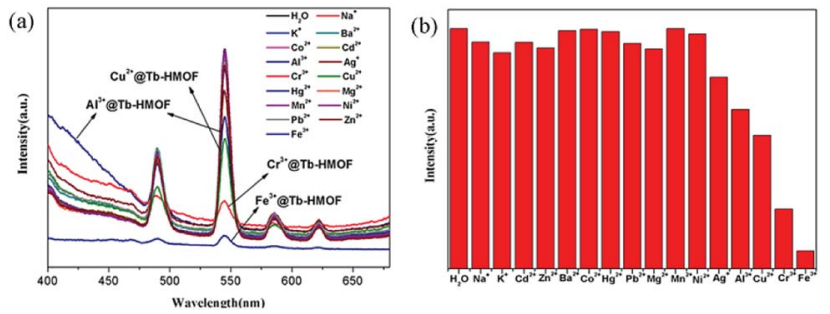

Fig. 8 (a) Emission spectra of Tb-HMOF (10 mg) dispersed in various nitrate salts aqueous solutions $\left(3 \mathrm{~mL}, 10^{-3} \mathrm{M}\right)$. (b) Cation selectivity of the $\mathrm{Tb}$ - $\mathrm{HMOF}\left(I_{0} / l\right)$ in $\mathrm{H}_{2} \mathrm{O}$.

upon the luminescence of $\mathrm{Tb}^{3+}$. For the incorporated $\mathrm{Na}^{+}, \mathrm{K}^{+}$, $\mathrm{Cd}^{2+}, \mathrm{Ba}^{2+}, \mathrm{Mg}^{2+}, \mathrm{Mn}^{2+}, \mathrm{Ni}^{2+}, \mathrm{Zn}^{2+}, \mathrm{Co}^{2+}, \mathrm{Hg}^{2+}$, or $\mathrm{Pb}^{2+}$, the effect on the luminescence intensity at $545 \mathrm{~nm}$ of Tb-HMOF is negligible. However, for the incorporated $\mathrm{Ag}^{+}, \mathrm{Cu}^{2+}, \mathrm{Cr}^{3+}, \mathrm{Al}^{3+}$, or $\mathrm{Fe}^{3+}$, they display different degrees of quenching on the fluorescence of $\mathrm{Tb}^{3+}$ with obviously distinguished spectra: $\mathrm{Ag}^{+}$, $\mathrm{Al}^{3+}$ or $\mathrm{Cu}^{2+}$ has a certain quenching effect on the luminescence intensity, whereas $\mathrm{Cr}^{3+}$ or $\mathrm{Fe}^{3+}$ has a rapidly quenching effect on the luminescence intensity, and especially for $\mathrm{Fe}^{3+}$ it can efficiently and completely quench the emission of $\mathrm{Tb}^{3+}$. In particular, accompanied by the quenching effect on the fluorescence of $\mathrm{Tb}^{3+}$, the incorporated $\mathrm{Al}^{3+}$ can largely enhance the ligandrelated emission (Fig. 8a). These results suggest that the fluorescence of Tb-HMOF is very sensible to $\mathrm{Fe}^{3+}, \mathrm{Cr}^{3+}$, and $\mathrm{Al}^{3+}$ ions, and perhaps has potential application in ion detection.

To further understand the fluorescent sensing behaviours of Tb-HMOF to $\mathrm{Fe}^{3+}, \mathrm{Cr}^{3+}$ and $\mathrm{Al}^{3+}$, concentration-dependent luminescence measurements were carried out. The assynthesized Tb-HMOF samples were ground and immersed in different concentrations of $\mathrm{Fe}^{3+}, \mathrm{Al}^{3+}$, or $\mathrm{Cr}^{3+}$, and then their luminescence spectra were recorded. As shown in Fig. 9 and $\mathrm{S} 15, \uparrow$ the emission intensity of Tb-HMOF suspension is rapidly quenched with increasing concentration $\mathrm{Fe}^{3+}$ or $\mathrm{Cr}^{3+}$. When the concentration reaches $5 \mathrm{mM}$ for $\mathrm{Fe}^{3+}$ or $30 \mathrm{mM}$ for $\mathrm{Cr}^{3+}$, the luminescence of $\mathrm{Tb}^{3+}$ is almost completely quenched.

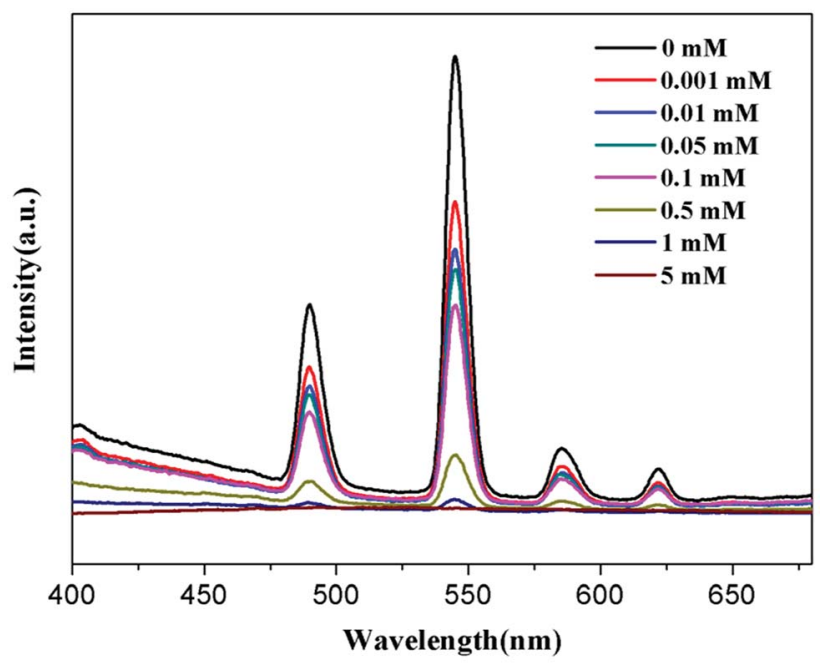

Fig. 9 Emission spectra of Tb-HMOF in aqueous solutions of various concentrations of $\mathrm{Fe}^{3+}$ under excitation at $352 \mathrm{~nm}$. 


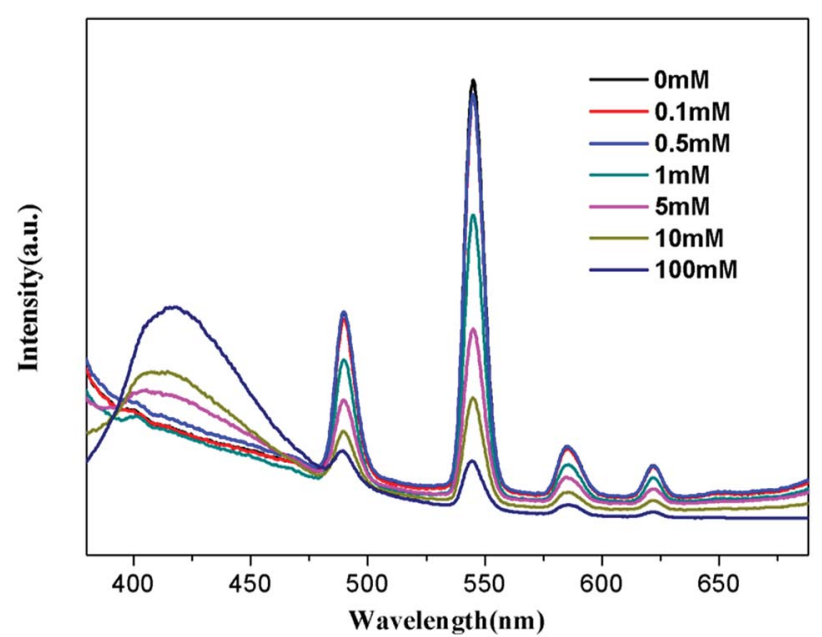

Fig. 10 Emission spectra of Tb-HMOF in aqueous solutions of various concentrations of $\mathrm{Al}^{3+}$ under excitation at $352 \mathrm{~nm}$.

Comparatively, the fluorescent quenching effect of $\mathrm{Fe}^{3+}$ on the Tb-HMOF is more quick and thorough than that of $\mathrm{Cr}^{3+}$. For the $\mathrm{Al}^{3+}$-incorporated sample, the luminescence intensity of $\mathrm{Tb}^{3+}$ decreases slowly and the emission of the ligand-related emission centered at $425 \mathrm{~nm}$ increases gradually with increasing concentration $\mathrm{Al}^{3+}$. When the $\mathrm{Al}^{3+}$ concentration reaches $10 \mathrm{mM}$, clear quenching of the luminescence of $\mathrm{Tb}^{3+}$ can be seen (Fig. 10). As the concentration of $\mathrm{Al}^{3+}$ increases to $100 \mathrm{mM}$, the luminescence of $\mathrm{Tb}^{3+}$ is nearly completely quenched and only the emission of the ligand can be observed. Further with the increase of $\mathrm{Al}^{3+}$ concentration, Tb-HMOF dissolves gradually, and finally forms a clear aqueous solution as the $\mathrm{Al}^{3+}$ concentration reaches $0.1 \mathrm{M}$. This phenomenon has been reported in previous literature. ${ }^{50}$

\section{Conclusions}

In summary, we have successfully synthesized a series of novel Ln-HMOFs based on chiral ligand ( $S$ )-5-(((1-carboxyethyl)amino) methyl)isophthalic acid $\left(\mathrm{H}_{3} \mathrm{~L}\right)$. All complexes are isostructural with $(3,6)$-connected homochiral frameworks whose phase purities and chirality are further confirmed by PXRD and CD studies, respectively. The luminescent investigation of 1-4 suggests that compounds 2 and 3 display the strong characteristic emissions of the corresponding $\mathrm{Eu}^{3+}$ and $\mathrm{Tb}^{3+}$ ions, while 1 and 4 exhibit blue emissions arising from ligand $(\mathrm{HL})^{2-}$. By doped different $\mathrm{Ln}^{3+}$ ions into single-phase Ln-HMOFs, the bimetallic Eu/Tb-HMOFs $\left[\left(\mathrm{Eu}_{x} \mathrm{~Tb}_{1-x}\right)_{2}(\mathrm{HL})_{2}\left(\mathrm{H}_{2} \mathrm{O}\right)_{4}\right] \cdot 2 \mathrm{Cl} \cdot 5 \mathrm{H}_{2} \mathrm{O}$ and trimetallic $\mathrm{Eu} / \mathrm{Gd} / \mathrm{Tb}-\mathrm{HMOF}\left[\left(\mathrm{Eu}_{0.1388} \mathrm{Gd}_{0.6108} \mathrm{~Tb}_{0.2504}\right)_{2}(-\right.$ $\left.\mathrm{HL})_{2}\left(\mathrm{H}_{2} \mathrm{O}\right)_{4}\right] \cdot 2 \mathrm{Cl} \cdot 5 \mathrm{H}_{2} \mathrm{O}$ have been successfully fabricated. The emission colors of bimetallic Eu/Tb-HMOFs can be tuned among green, yellow, orange, orange-red, and red by adjusting the doping concentration of $\mathrm{Eu}^{3+}$ ions into the Tb-HMOF. Very important, the trimetallic doped $\mathrm{Eu} / \mathrm{Gd} / \mathrm{Tb}-\mathrm{HMOF}\left[\left(\mathrm{Eu}_{0.1388^{-}}\right.\right.$ $\left.\left.\mathrm{Gd}_{0.6108} \mathrm{~Tb}_{0.2504}\right)_{2}(\mathrm{HL})_{2}\left(\mathrm{H}_{2} \mathrm{O}\right)_{4}\right] \cdot 2 \mathrm{Cl} \cdot 5 \mathrm{H}_{2} \mathrm{O}$ features white light emission upon excitation at $355 \mathrm{~nm}$, whose emission can also be switched between different colors when excited with different ultraviolet light. Furthermore, the fluorescence response of Tb-HMOF to various usual metal ions, and especially fluorescent sensing behaviours to $\mathrm{Fe}^{3+}, \mathrm{Cr}^{3+}$ and $\mathrm{Al}^{3+}$ has been preliminarily investigated.

\section{Conflicts of interest}

The authors declare no competing financial interest.

\section{Acknowledgements}

We gratefully acknowledge financial support from the National Natural Science Foundation of China (21271157), and the Foundation and Research in Cutting-Edge Technologies in the Project of Henan Province (122300410092).

\section{Notes and references}

1 M. Roushan, X. Zhang and J. Li, Angew. Chem., Int. Ed., 2012, 51, 436-439.

2 Y. C. Liao, C. H. Lin and S. L. Wang, J. Am. Chem. Soc., 2005, 127, 9986-9987.

3 P. C. P. Lima, F. A. Almeida Paz, R. A. S. Ferreira, V. De Zea Bermudez and L. S. D. Carlos, Chem. Mater., 2009, 21, 5099-5111.

4 Y. S. Zhao, H. B. Fu, F. Q. Hu, A. D. Peng, W. S. Yang and J. N. Yao, Adv. Mater., 2008, 20, 79-83.

5 G. He, D. Guo, C. He, X. Zhang, X. Zhao and C. Duan, Angew. Chem., Int. Ed., 2009, 48, 6132-6135.

6 Q. Ju, D. Tu, Y. Liu, R. Li, H. Zhu, J. Chen, Z. Chen, M. Huang and X. Chen, J. Am. Chem. Soc., 2012, 134, 1323-1330.

7 J. Rocha, L. D. Carlos, F. A. A. Paz and D. Ananias, Chem. Soc. Rev., 2011, 40, 926-940.

8 A. Schoedel, M. Li, D. Li, M. O'Keeffe and O. M. Yaghi, Chem. Rev., 2016, 116, 12466-12535.

9 J. C. G. Bünzli, Chem. Rev., 2010, 110, 2729-2755.

10 L. D. Carlos, R. A. S. Ferreira, V. De Zea Bermudez, B. JulianLopez and P. Escribano, Chem. Soc. Rev., 2011, 40, 536-549.

11 F. F. Chen, Z. Q. Chen, Z. Q. Bian and C. H. Huang, Coord. Chem. Rev., 2010, 254, 991-1010.

12 J. Heine and K. Muller-Buschbaum, Chem. Soc. Rev., 2013, 42, 9232-9242.

13 H. Jeong, B. Lee, S. Byeon, H. Jeong, B. Lee and S. Byeon, ACS Appl. Mater. Interfaces, 2016, 8, 10946-10953.

14 L. Armelao, D. Belli Dell Amico, L. Bellucci, G. Bottaro, L. Labella, F. Marchetti and S. Samaritani, Inorg. Chem., 2016, 55, 939-947.

15 Q. Tang, S. X. Liu, Y. W. Liu, D. F. He, J. Miao, X. Q. Wang, Y. J. Ji and Z. P. Zheng, Inorg. Chem., 2014, 53, 289-293.

16 X. Yang, X. Lin, Y. Zhao, Y. S. Zhao and D. Yan, Angew. Chem., Int. Ed., 2017, 56, 7853-7857.

17 M. L. Ma, C. Ji and S. Q. Zang, Dalton Trans., 2013, 42, 1057910586.

18 J. Rong, W. Zhang and J. Bai, RSC Adv., 2016, 6, 103714103723.

19 Y. W. Zhao, F. Q. Zhang and X. M. Zhang, ACS Appl. Mater. Interfaces, 2016, 8, 24123-24130. 
20 H. Xu, C. S. Cao, X. M. Kang and B. Zhao, Dalton Trans., 2016, 45, 18003-18017.

21 K. X. Shang, J. Sun, D. C. Hu, X. Q. Yao, L. H. Zhi, C. D. Si and J. C. Liu, Cryst. Growth Des., 2018, 18, 2112-2120.

22 Y. Y. An, L. P. Lu, S. S. Feng and M. L. Zhu, CrystEngComm, 2018, 20, 2043-2052.

23 Y. Yang, F. L. Jiang, C. P. Liu, L. Chen, Y. L. Gai, J. Pang, K. Z. Su, X. Y. Wan and M. C. Hong, Cryst. Growth Des., 2016, 16, 2266-2276.

24 J. Rong, W. Zhang and J. Bai, CrystEngComm, 2016, 18, 77287736.

25 K. Kim, J. S. Seo, D. Whang, H. Lee, S. I. Jun, J. Oh and Y. J. Jeon, Nature, 2000, 404, 982-986.

26 M. Yoon, R. Srirambalaji and K. Kim, Chem. Rev., 2012, 112, 1196-1231.

27 Y. Liu, W. M. Xuan and Y. Cui, Adv. Mater., 2010, 22, 41124235.

28 L. Ma, C. Abney and W. Lin, Chem. Soc. Rev., 2009, 38, 12481256.

29 K. K. Bisht, B. Parmar, Y. Rachuri, A. C. Kathalikattil and E. Suresh, CrystEngComm, 2015, 17, 5341.

30 Z. G. Gu, C. Zhan, J. Zhang and X. Bu, Chem. Soc. Rev., 2016, 45, 3122-3144.

31 K. Mo, Y. H. Yang and Y. Cui, J. Am. Chem. Soc., 2014, 136, 1746-1749.

32 Z. G. Gu, W. Q. Fu, M. Liu and J. Zhang, Chem. Commun., 2017, 53, 1470-1473.

33 Z. X. Xu, Y. X. Tan, H. R. Fu, J. Liu and J. Zhang, Inorg. Chem., 2014, 53, 12199-12204.

34 Q. Yue, J. Yang, G. H. Li, G. D. Li and J. S. Chen, Inorg. Chem., 2006, 45, 4431-4439.

35 C. H. Gao, L. Zhang, G. F. Hou, D. S. Ma, W. H. Jiang and Y. H. Yu, Inorg. Chem. Commun., 2017, 78, 70-73.
36 L. Sun, G. F. Hou, W. H. Jiang, Q. Huang, Y. H. Yu and J. S. Gao, Polyhedron, 2017, 129, 55-59.

37 T. Liu, Y. H. Yu, H. Z. Zhang, W. H. Jiang, J. S. Gao and G. F. Hou, Cryst. Growth Des., 2017, 17, 1788-1795.

38 X. Wang, K. Zhang, L. Lv, R. Chen, W. Wang and B. Wu, Cryst. Growth Des., 2018, 18, 1799-1808.

39 H. S. Jang, H. Yang, S. W. Kim, J. Y. Han, S. G. Lee and D. Y. Jeon, Adv. Mater., 2008, 20, 2696-2702.

40 Y. Lu and B. Yan, Chem. Commun., 2014, 50, 15443-15446.

41 G. N. Wyszecki and W. S. Stiles, Color Science: Concepts and Methods, Quantitative Data, and Formulae, John Wiley \& Sons, New York, Wiley classics library edn, 2000.

42 G. M. Sheldrick, SADABS, Program for Empirical Absorption Correction of AreaDetector Data, University of Götingen, Götingen, Germany, 1997.

43 G. M. Sheldrick, SHELXS-97, Program for X-ray Crystal Structure Determination, University of Göttingen: Göttingen, Germany, 1997.

44 G. M. Sheldrick, SHELXS-97, Program for X-ray Crystal Structure Refinement, University of Göttingen: Göttingen, Germany, 1997.

45 A. L. Spek, J. Appl. Crystallogr., 2003, 36, 7-13.

46 B. Wu, S. Wang, R. Wang, J. Xu, D. Yuan and H. Hou, Cryst. Growth Des., 2013, 13, 518-525.

47 J. P. Costes, T. Yamaguchi, M. Kojima and L. Vendier, Inorg. Chem., 2009, 48, 5555-5561.

48 Z. J. Li, X. Y. Li, Y. T. Yan, L. Hou, W. Y. Zhang and Y. Y. Wang, Cryst. Growth Des., 2018, 18, 2031-2039.

49 K. Liu, H. You, Y. Zheng, G. Jia, Y. Song, Y. Huang, M. Yang, J. Jia, N. Guo and H. Zhang, J. Mater. Chem., 2010, 20, 32723279.

50 L. H. Cao, F. Shi, W. M. Zhang and S. Q. Zang, Chem.-Eur. J., 2015, 21, 15705-15712. 